\title{
The Slope Comprehensive Reinforcement Design Scheme Optimization Based on the Limit Equilibrium Method
}

\author{
Shiguo Sun ${ }^{1}$, Yinghai Zhang ${ }^{1, a^{*}}$, Jianqiang Wang $^{1}$, \\ Zhenhua $\mathrm{Su}^{1}$, Shaojie Feng ${ }^{1}$ \\ ${ }^{1}$ North China University of Technology, Beijing 100144 \\ $a^{*} z y h x h w y @ y e a h . n e t$
}

\begin{abstract}
Key words: open-pit mine, slope cutting and unloading, slope safety, sliding field, optimized government
\end{abstract}

Abstract: The composition of the open-pit mine slope is a dynamic process. With the arriving of the exploitation of the deep and slope, the slope height, slope angle increases for years and forms high-steep slope. Its security seriously restricts safety production. This article will take the steep slopes of one Open-pit Coal Mine in mining process as an example, and focus on the side slope stability analysis and the safety control. Furthermore, slip field theory and limit equilibrium method will be used to study on slope stability of present and mined slope. Combined with the production, the systematic research of the slope reinforcement measures are carried out on the premise of guaranteed safety. And optimization of slope landslide reinforcement scheme will be proposed.

\section{Introduction}

For a long time, the study of slope stability evaluation method is the key of the slope engineering, how to obtain stability evaluation method can reflect the actual situation of the geotechnical slope is the relentless pursuit of the goal scholars and experts engineering. The common methods of slope stability analysis in the project are divided into quantitative and qualitative analysis. Qualitative analysis method (historical analysis method, engineering geological analogy method, graphical method, CSMR evaluation system, model analysis and parameter inversion analysis, etc.) summarizes the various factors that affect slope stability in the project, and it can quickly make the appropriate assessment on the slope stability status and development trend of slope. However, the deficiency is that it can only be used to determine whether the slope is stable, can't give a specific slope stability safety coefficient. Quantitative analysis method (limit equilibrium analysis and numerical analysis, etc.) applies mechanics theory and method, relies on classical mathematical equation of physics to solve the slope stability coefficient, finally calculated by computer program software analysis and smooth state of stress and strain distribution in the body, software analysis is used by a computer program to calculate the stress-strain distribution state in sliding mass, so as to achieve the aim of slope stability evaluation and prediction. ${ }^{[1,2,3]}$ In the quantitative analysis method, limit equilibrium method is widely used and accepted in engineering because of its clear, simple physical mechanics concept, so it is a quantitative analysis method of traditional and classic.

Based on slip field theory and a variety of limit equilibrium analysis methods, the high-steep slope at the western part of an open-pit mine section 348 stable state is analyzed. It is concluded that the region is in critical condition. In order to ensure safety in production, underground drainage, local load reduction and prestressed cable are used.

\section{Engineering geology and calculation parameters}

\subsection{Engineering geology}

The mine affected by the seismic activity and mostly relatively strong earthquake zone. And there have been frequent severe earthquake disasters. According to the "China basic seismic intensity zoning map", the mine area is located fortification intensity 7. The main western and northwest buttock outcrops Gejiu of Middle Triassic (T2g), New Tertiary (N) and quaternary strata (Q). Its basement forms coal in Tertiary sedimentary strata time, and produces the syncline structure which 
likes a boat. Its inclination angle waves between $9^{\circ}$ and $16^{\circ}$, and there are faults F7、F8 and F9 in the coal.

In order to ensure safety and help the bottom of the west wall to stay stability, this paper has taken the section 348 as an example to optimization design. According to the previous survey results data and the needed time all of the coal being removed, three steps are taken to achieve clearing the wall and unloading.

\subsection{Calculation parameters}

The section 348 is a high-steep slope. The height of the slope is $12 \mathrm{~m}$ and its slope toe is 18 degrees. The current slope engineering geology distribution map is shown in Fig.1. Rock slope consists of lime stone, claystone, lignite and faults F7, F8, F9 (Table 1). After a series of search, it's most dangerous sliding surface position is shown in Fig.2.

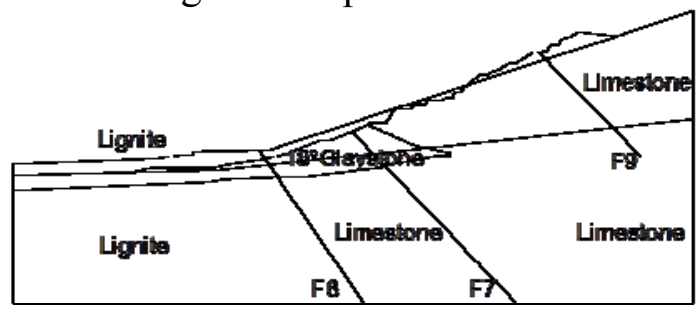

Fig. 1 Current slope engineering geology distribution map of section 348

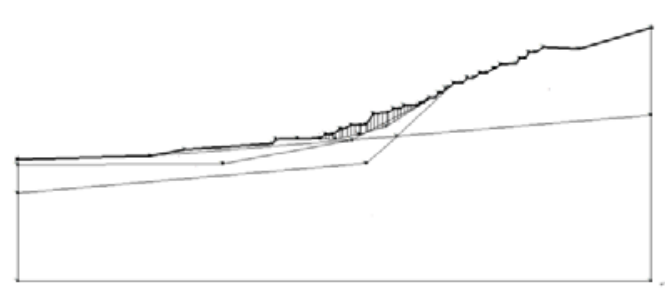

Fig.2 The dangerous slip surface of section 348

Table 1 Physical an mechanical properties of rock and soil indicators

\begin{tabular}{|c|c|c|c|c|c|c|c|}
\hline \multirow{2}{*}{$\begin{array}{c}\text { Order } \\
\text { number }\end{array}$} & $\begin{array}{c}\text { The rock } \\
\text { and soil } \\
\text { bed }\end{array}$ & $\begin{array}{c}\text { Natural } \\
\text { state }\end{array}$ & $\begin{array}{c}\text { Water-saturated } \\
\text { state }\end{array}$ & $\begin{array}{c}\text { Natural } \\
\text { state }\end{array}$ & $\begin{array}{c}\text { Water- } \\
\text { saturated } \\
\text { state }\end{array}$ & $\begin{array}{c}\text { Natural } \\
\text { state }\end{array}$ & $\begin{array}{c}\text { Water-saturated } \\
\text { state }\end{array}$ \\
\hline 1 & Lignite & 20.55 & 21 & 20.95 & 0 & 9.85 & 9.2 \\
\hline 2 & Limestone & 25 & 27 & 81 & 81 & 16.45 & 16.45 \\
\hline 3 & clay & 20.55 & 23.5 & 20.95 & 19 & 9.85 & 9.2 \\
\hline
\end{tabular}

\section{Calculation section and the safety control standard of slope}

Up to now, Chinese slope (including natural slope) design and construction have not formed a unified norms and standards. By a meta-analysis of the high-steep features of high-steep slope, engineering complex geological conditions, rock distribution diversification, fracture development of rock and soil, rich in natural precipitation conditions, and referring to the relevant standards and regulations and large number of slope engineering practices from domestic and foreign, the stable and secure high-steep slope coefficient values were determined ${ }^{[4,5]}$. The coefficient values are shown in Table 2:

Table 2 The control standards of overall safety factor of slope

\begin{tabular}{|c|c|c|c|c|}
\hline Working condition & $\begin{array}{c}\text { Natural } \\
\text { state }\end{array}$ & $\begin{array}{c}\text { Precipitation } \\
\text { state }\end{array}$ & $\begin{array}{c}\text { Earthquake and } \\
\text { Natural }\end{array}$ & $\begin{array}{c}\text { Earthquake and } \\
\text { Precipitation }\end{array}$ \\
\hline Control standards & 1.30 & 1.20 & 1.10 & 1.05 \\
\hline
\end{tabular}

\section{The stability analysis and treatment measures of current slop}

\subsection{The stability analysis of current slop}

Four kinds of limit equilibrium method were used to evaluate the stability of section $348^{[6]}$. The calculation results are shown in Table 3.It shows that the slop is in a non-steady state when water and earthquakes are considered. The average safety factor of the section is 1.05 , which means landslides would happen at any time. It will be bad to the coal extraction in the future. Therefore, the slope must be timely reinforced by appropriate measures. 
Table 3 The stability calculations of current slope of section 348

\begin{tabular}{|c|c|c|c|c|c|}
\hline Calculation method & Ordinary & Bishop & Janbu & Morgenstern-Price & $\begin{array}{c}\text { Mean } \\
\text { value }\end{array}$ \\
\hline Working condition & 1.076 & 1.101 & 1.069 & 1.115 & 1.090 \\
\hline Earthquake and Water & 1.025 & 1.046 & 1.016 & 1.063 & 1.038 \\
\hline
\end{tabular}

In addition, the slope deformation monitoring network measured data and site visit indicate the west wall deformation body have been converted from the creeping stage to the acceleration slip stage. If don't take timely treatment measures and leave it alone, the slip surface will be most likely completely through, and cause a devastating landslide. Therefore, effective measures should be taken to prevent the slop from break to ensure the safety of coal mining in the future.

\subsection{The treatment measures of current slop}

Theoretical research and engineering practice shows that water is a critical factor in the formation of geological disasters. It will not only reduce the strength of engineering rock (soil), but also to reduce the stability of the slope. Since the study period, the slope in coal mining stage, are temporary slope, so the governance of slope should ensure the safety of mining and do not produce a large deformation that will affect the normal use of the surrounding buildings and roads, etc. Therefore, load shedding and precipitation are used to achieve a stable slope.

In this project, the surface water resources of the area are about 0.999 million $\mathrm{m}^{3} /$ year. Due to the slope has built complete surface drainage systems, therefore surface water less impacts on the slope. Quaternary phreatic water is shallow mining depth, limited recharge and little effect on the slope, so surface drainage is introduced. Tertiary bedrock fissure water has a certain amount of recharge and shallow depth. For its great influence on slope stability, so dewatering well location method should be taken. Arranged in its recharge and runoff area a certain number of pumping wells, which can effectively reduce fracture water groundwater levels, and groundwater can be extracted at the same time as production and living water. Because deep karst water has large supply capacity, so it should be processed by the existing system at the bottom of the pit precipitation.

Considering the duration, inputs and quick effectiveness of implementation, lowering water level and auxiliary cutting slope methods are used to governance. A preliminary determination on the basis of the original, set drop pools on the fringes of the slope make water level drop 10m. Field theory method is used to search dangerous sliding surface after slope precipitation and cutting. The results are shown in figure 4 and the calculated safety factor are shown in Table 4.

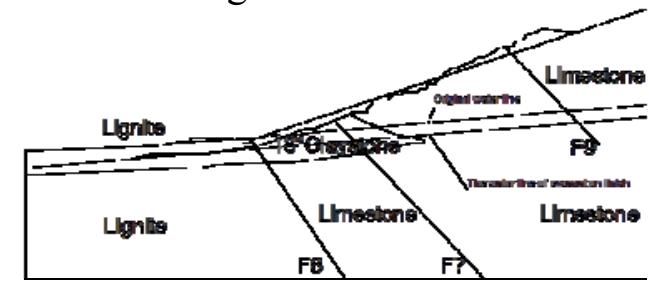

Fig.3 Slope cutting and lower water level of section 348

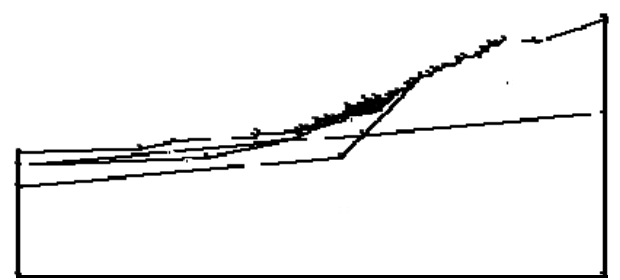

Fig.4 Dangerous sliding surface of section 348

Table 4 The stability evaluation results after water level drop $10 \mathrm{~m}$ and slope cutting

\begin{tabular}{|c|c|c|c|c|c|}
\hline Calculation method & Ordinary & Bishop & Janbu & Morgenstern-Price & Mean value \\
\hline Stability coefficient & 1.116 & 1.173 & 1.139 & 1.186 & 1.154 \\
\hline
\end{tabular}

As it can be seen from the above analysis results, the stability factor of the slope has increased about 12 percent after dewatering measurement was employed. Although the local potential slip surface is still existent, the probability of landslide is relatively small, and the stability of slope is significantly improved. This shows that the drainage program has good results, and it can be used.

\section{The stability analysis and treatment measures of western buttock}

\subsection{The stability analysis of western buttock}

Four kinds of limit equilibrium method were used to evaluate the stability of section 348 after mining. The calculation results are shown in Table 5. Maximum slope safety factor of section 348 is 
1.038 , and the minimum is 0.846 , with an average safety factor $\mathrm{K}=0.962$. It shows that it has exceeded the limits of the state in an unstable state, and landslides may occur at any time. If it encounters a rainy season, the water content increases will increase the probability of the landslide, so appropriate reinforcement measures should be taken in potential landslide locations.

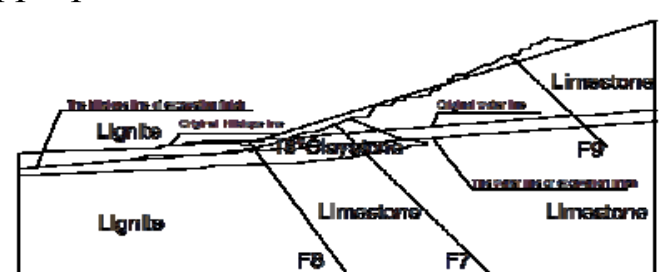

Fig.5 Slope engineering of final geological profile of section 348

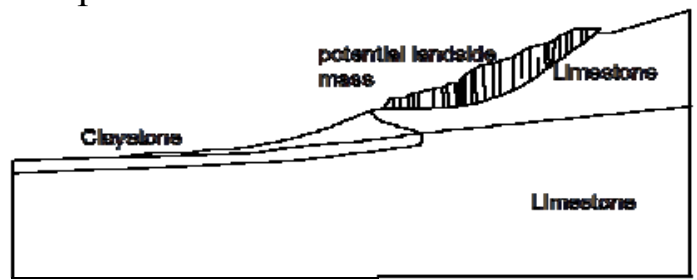

Fig.6 Final highwall of dangerous sliding surface of section 348

Table 5 The stability calculations of final highwall slop of section 348

\begin{tabular}{|c|c|c|c|c|c|}
\hline Calculation method & Ordinary & Bishop & Janbu & Morgenstern-Price & $\begin{array}{c}\text { Mean } \\
\text { value }\end{array}$ \\
\hline Stability coefficient & 0.846 & 1.038 & 0.948 & 1.015 & 0.962 \\
\hline
\end{tabular}

\subsection{The treatment measures of western buttock}

The most commonly used methods of slope reinforcement are: cutting slope and unloading, presser foot slope, drainage (ditches, slope inside drain), slope protection, retaining (retaining wall, slide pile), anchor (cable) and comprehensive strengthening method. But in the reinforcement design and construction it should be adapted to local conditions as far as possible, otherwise they will cause many problems and could not achieve ideal outcome because of itself existing some shortcomings or inappropriate application, even cause serious engineering accident.

In this project, the surface of the slop are loose soil, so soil and rock fall at the junction accumulates a lot of infiltration of surface water for the surface is extremely easy infiltration of permeated. When meet the rainy season, the strength of the soil slope near the boundary surface will be affected by the influence of water and decreased significantly with the infiltration of rainwater, which will induce the slope sliding damage along the soil interface. Considering the engineering geological characteristics and hydrogeological situation of open-pit mine, this paper will mainly consider the reinforcement schemes from cutting slope and unloading and prestressed anchor.

\subsubsection{Cutting slope and unloading}

When determine the lightening starting point to avoid the upper slope rock tumbling directly to the slope toe. The bottom of the overlying coal seam location along the border and clay rock is regarded as a starting point in lightening level. And here forms a lightening security platform, as shown in figure 7, the upper slope Angle is $24^{\circ}$.

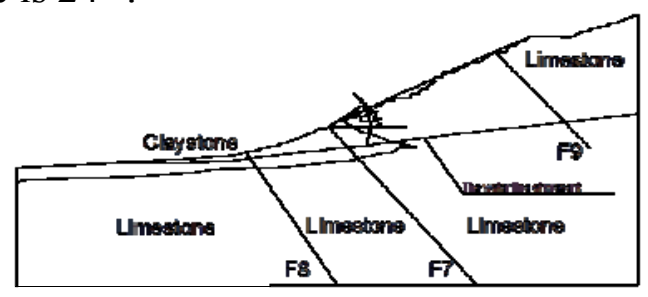

Fig.7 Slope engineering of final highwall geological profile

Scenario 1 : After preliminary lightening and precipitation, the current slope is in stable state with an average slope safety factor of 1.154. Because the lignite reservoir of section 348 is thinner than other section, therefore it is unnecessary to mine step by step. Thus slope top and middle respectively are reduced load and take top slope Angle $24^{\circ}$. In the central of the slope adjust measures to local conditions, and $20 \mathrm{~m}$ is taken as the security platform.

Scenario 2: The load shedding is used in top and middle of the slope, and three load shedding platforms are set and take top slope Angle $22^{\circ}$;

Scenario 2: The load shedding is used in top and middle of the slope, and three load shedding platforms are set and take top slope Angle 21 ${ }^{\circ}$; 
Scenario 2: The load shedding is used in top and middle of the slope, and three load shedding platforms are set and take top slope Angle $20^{\circ}$;

Table 6 The stability coefficient of different slope scenarios

\begin{tabular}{|c|c|c|c|c|c|c|}
\hline $\begin{array}{c}\text { Calculation } \\
\text { method } \\
\text { Stability coefficient }\end{array}$ & Ordinary & Bishop & Janbu & Morgenstern-Price & $\begin{array}{c}\text { Mean } \\
\text { value }\end{array}$ & $\begin{array}{c}\text { Earth } \\
\text { volume } \\
\left(\mathrm{m}^{3} / \mathrm{m}\right)\end{array}$ \\
\hline Scenario 1 & 0.988 & 1.024 & 0.963 & 1.030 & 1.001 & 2084.1788 \\
\hline Scenario 2 & 1.109 & 1.127 & 1.104 & 1.129 & 1.117 & 4537.6663 \\
\hline Scenario 3 & 1.110 & 1.126 & 1.105 & 1.129 & 1.118 & 5486.7618 \\
\hline Scenario 4 & 1.174 & 1.216 & 1.173 & 1.229 & 1.198 & 11585.431 \\
\hline
\end{tabular}

\subsubsection{The strengthening method of prestressed anchor ropes}

The proposed mining slope stability evaluation result shows that the slope is in dangerous condition, and it would produce landslide anytime. The sliding surface partition shows in Fig.8. The slope is divided into 12 body slide bars. They are $30 \mathrm{~m}$ wide. Transfer coefficient method is used to calculate the landslide thrust. 1.15 is taken as the slope safety factor. The landslide thrust of the exit is $19400.838 \mathrm{kN} / \mathrm{m}$.

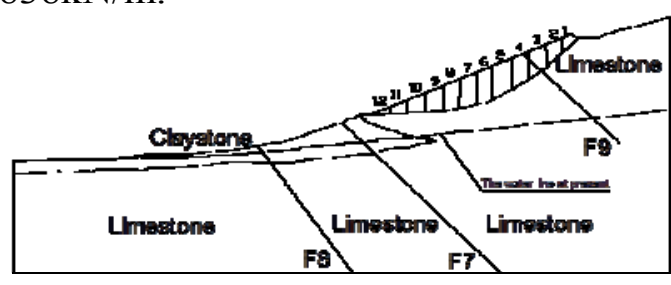

Fig.8 Quasi sliding surface after excavation slope diagram of section 348

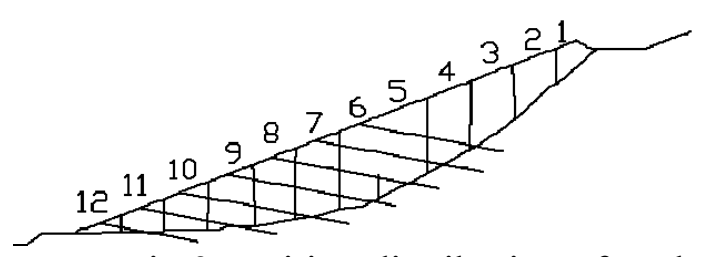

Fig.9 Position distribution of anchor cable reinforcement design

The anchorage angle is $\beta=15^{\circ}$ after optimization. $2 \mathrm{~m}$ is used as the anchor spacing, and take the design safety coefficient $F=2.5$. Ren 7 rows are taken as the anchor cable for design. Because the landslide of section 348 is thick, so take the average length of each anchor $100 \mathrm{~m}$ (Fig.9). The stability evaluation result of the slope after reinforcement shows in Table 7.

Table 7 The stability evaluation results of section 348 after the anchor cable reinforcement

\begin{tabular}{|c|c|c|c|c|c|}
\hline Calculation method & Ordinary & Bishop & Janbu & Morgenstern-Price & Mean value \\
\hline Stability coefficient & 1.044 & 1.057 & 1.055 & 1.076 & 1.058 \\
\hline
\end{tabular}

\subsubsection{The Comprehensive scenario design of reinforcement}

In the scenarios of cutting slope and unloading, scenarios 2, 3 and 4 can meet stability requirements only by lightening, and it need not add prestressed anchor cable ${ }^{[7]}$, so the comprehensive reinforcement scenario is adopted on the basis of lightening scenario 1 . The prestressed anchors are used on the lower part of the slope. The sliding surface of after cutting slope and unloading is shown in Fig.10.

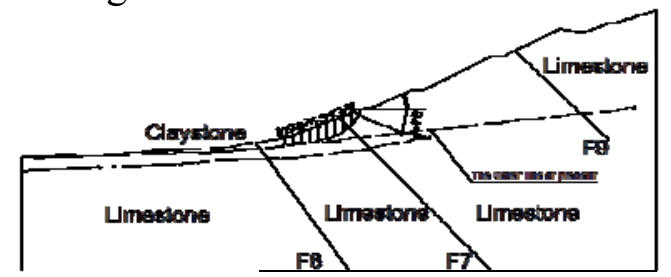

Fig.10 The scenario of load shedding of section 348

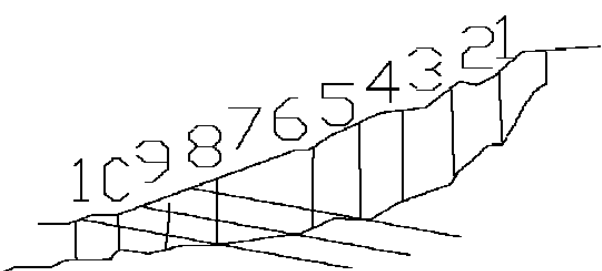

Fig. 11 The division schematic of slip surface after load shedding

The slope is divided into 12 body slide bars. They are $15 \mathrm{~m}$ wide. Transfer coefficient method is used to calculate the landslide thrust. 1.15 is taken as the slope safety factor. The landslide thrust of the exit is $1517.3 \mathrm{kN} / \mathrm{m}$.

The anchorage angle is $\beta=15^{\circ}$ after optimization. $2 \mathrm{~m}$ is used as the anchor spacing, and take the design safety coefficient $F=2.5$. Ren 7 rows is taken as the anchor cable for design. Because the landslide of section 348 is thick, so take the average length of each anchor $70 \mathrm{~m}$ (Fig.11). The stability evaluation result of the slope after reinforcement shows in Table 8 . 
Table 8 The stability evaluation results of section 348 after the anchor cable reinforcement

\begin{tabular}{|l|c|c|c|c|c|}
\hline Calculation method & Ordinary & Bishop & Janbu & Morgenstern-Price & Mean value \\
\hline Stability coefficient & 1.119 & 1.144 & 1.116 & 1.207 & 1.147 \\
\hline
\end{tabular}

\section{Conclusions}

The conclusions can be drawn by stability evaluation and governance analysis of high-steep slope of section 348:

(1)It will have to peel large slop rock and have a heavy workload. What's more, it will take a longer period, and not conducive to maintain the stability of the slope. So the Three-step lightening measure is taken according to actual situation;

(2)Stability analysis of the current slope shows that when water and earthquakes are considered, the slop is in a critical state or dangerous state. But the current existing flood control and water drainage measures can basically guarantee stability of the slope;

(3)A series of measures, such as internal drainage process, have been taken to consolidate the slope safety after drilling to the final wall. It can not only guarantee the stability of the slope, but also can greatly reduce the stripping quantity of rock and soil mass, thus it can reduce the project cost and improve the economic benefit;

(4)In cutting slope and unloading, anti-sliding retaining wall project, cutting slope lightening supplemented and prestressed anchor cable reinforcement, the third program is the recommended program, which can achieve the desired goal of governance and is economic rationality.

\section{Acknowledgements}

This work was finally supported by National Natural Science Foundation of China (41172250), Scientific and Technology support Project of National Twelfth Five-Year Plan (2012BAK09B06), The Innovative Team Project of Beijing (IDHT20140501), The scientific research base construction and scientific innovation platform of Beijing, and The scientific research base construction and scientific innovation platform of Beijing, The Science and Technology Achievements Transformation Project of Beijing. Rock burst build of micro-seismic monitoring and early warning system (XN083), New type of anchor reinforcement technique field test research and graduate student ability training (XN107).

\section{References:}

[1] Shengwu Song, Manfu Gong, Chengdi Lei. Study stability of high rock slope in hydropower engineering, J. Journal of rock mechanics and engineering, (2006) 226-237.

[2] Zhong Zhou, Manfu Gong, Chengdi Lei. Experimental research on stability of jinping high slope with three-dimensional geomechanical model,J. Journal of rock mechanics and engineering, (2006) 2298-2304.

[3] Zhaohui Wang, Shengxie Xiao, Wenfang Liu. Comparison and analysis of slope stability calculation method, J. Journal of Chongqing Jiaotong institute, (2005) 99-103.

[4] Industry design standards of the People's Republic of China. Highway drainage design criterion (JTG/TD33-2012), (S).Beijing, China Communications Press, (2012).

[5] Industry design standards of the People's Republic of China. Construction Side slope Engineering technology Standard (GB50330-2013), (S).Beijing, China Communications Press, (2013).

[6] Zhifei Song, Qun Wang, Binbin Sun. Slope Stability Evaluation and Treatment Scheme After Mining Disturbance[J]. Safety in Coal Mines, (2015), 46(6): 216-219.

[7] Xianghua Tang, Yan He. The application of prestressed anchor cable anti-slide pile in the collapse of the deposit, J. Yunnan hydropower, (2015)57-62. 